\title{
PENGARUH MODEL PEMBELAJARAN TRIKAYA PARISUDHA BERBASIS MASALAH TERHADAP SIKAP SOSIAL DAN HASIL BELAJAR IPS
}

\author{
I Gede Sadhu Satwika Pasek1, I Komang Sudarma², I Gede Astawan³
}

\begin{abstract}
${ }^{1}$ Prodi Pendidikan Guru Sekolah Dasar, Universitas Pendidikan Ganesha Singaraja, Indonesia
${ }^{2}$ Prodi Teknologi Pendidikan, Universitas Pendidikan Ganesha Singaraja, Indonesia

${ }^{3}$ Prodi Pendidikan Guru Sekolah Dasar, Universitas Pendidikan Ganesha Singaraja, Indonesia

e-mail: sadhu.satwika27@gmail.com¹, ikomangsudarma@undiksha.ac.id ${ }^{2}$, igedeastawan@undiksha.ac.id ${ }^{3}$
\end{abstract}

\begin{abstract}
Abstrak
Penelitian ini bertujuan untuk mengetahui: 1) pengaruh model pembelajaran Trikaya Parisudha berbasis masalah terhadap sikap sosial dan hasil belajar IPS 2) pengaruh model pembelajaran Trikaya Parisudha berbasis masalah terhadap sikap sosial, dan 3) pengaruh model pembelajaran Trikaya Parisudha berbasis masalah terhadap hasil belajar IPS. Penelitian ini merupakan penelitian eksperimen semu (quasi experiment) dengan desain nonequivalent posttest only control group. Jumlah populasi dalam penelitian ini adalah seluruh kelas IV SD di Gugus IV Kecamatan Susut yang terdiri dari 6 kelas dengan jumlah 115 siswa. Selanjutnya ditentukan sampel dengan menggunakan teknik Random Sampling dan didapatkan 2 sekolah dengan jumlah 45 siswa yang terdiri dari SD Negeri 3 Abuan sebagai kelompok eksperimen dengan jumlah 26 siswa dan SD Negeri 2 Susut sebagai kelompok kontrol dengan jumlah 19 siswa. Data sikap sosial siswa dikumpulkan menggunakan kuesioner dan data hasil belajar IPS dikumpulkan menggunakan tes pilihan ganda. Data dianalisis dengan statistik deskriptif dan Manova. Hasil penelitian menunjukkan bahwa: 1) secara simultan, terdapat perbedaan model pembelajaran Trikaya Parisudha berbasis masalah terhadap sikap sosial dan hasil belajar IPS. 2) terdapat perbedaan model pembelajaran Trikaya Parisudha berbasis masalah terhadap sikap sosial, dan 3) terdapat perbedaan model pembelajaran Trikaya Parisudha berbasis masalah terhadap hasil belajar IPS. Berdasarkan temuan tersebut, dapat disimpulkan bahwa moel pembelajaran Trikaya Parisudha berbasis masalah berpengaruh positif terhadap sikap sosial dan hasil belajar IPS.
\end{abstract}

Kata-kata kunci: pembelajaran berbasis masalah, trikaya parisudha, sikap sosial, hasil belajar IPS

\begin{abstract}
This study aims to determine: 1) the effect of the problem-based Trikaya Parisudha learning model on social attitudes and social studies learning outcomes 2) the influence of the problem-based Trikaya Parisudha learning model on social attitudes, and 3) the problem-based influence of the Trikaya Parisudha learning model on social studies learning outcomes. This research is a quasi experiment with a nonequivalent posttest only control group design. The total population in this study was all fourth grade elementary school in Cluster IV Susut District which consisted of 6 classes with the number 115 of students. The samples were then determined by using Random Sampling technique and obtained 2 schools with 45 students consisting of SD Negeri 3 Abuan as an experimental group with a total of 26 students and SD Negeri 2 Susut as a control group with a total of 19 students. Data on students' social attitudes were collected using questionnaires and social studies learning outcomes data were collected using multiple choice tests. Data were analyzed by descriptive statistics and Manova. The results showed that: 1) simultaneously, there were differences in the problem-based Trikaya Parisudha learning model on social attitudes and social studies learning outcomes. 2) there are differences in the Trikaya Parisudha learning model
\end{abstract}


based on the problem of social attitudes, and 3) there are differences in the Trikaya Parisudha learning model based on the problem of social studies learning outcomes. Based on these findings, it can be concluded that the problem-based model of the Trikaya Paris learning model has a positive effect on social attitudes and social studies learning outcomes.

\section{Keywords: Learning based on social, Trikaya Parisudha, social attitudes, social studies learning outcomes.}

\section{PENDAHULUAN}

Pendidikan merupakan salah satu proses yang dapat meningkatkan kualitas sumber daya manusia untuk mengembangkan potensi yang ada dalam diri manusia. Menurut Trianto (2009:1) "pendidikan adalah salah satu bentuk perwujudan kebudayaan manusia yang dinamis dan sarat perkembangan serta perubahan. Oleh karena itu, perubahan dan perkembangan dalam bidang pendidikan adalah hal yang memang seharusnya terjadi sejalan dengan perubahan ke arah perbaikan". Dalam pendidikan pada semua tingkat perlu terus-menerus dilakukan sebagai antisipasi kepentingan masa depan. Hal ini sejalan dengan makna sitem pendidikan nasional. Dalam UU No. 20 tahun 2003 tentang Sistem Pendidikan Nasional, dijelaskan bahwa pendidikan adalah usaha sadar dan terencana untuk mewujudkan suasana belajar dan proses pembelajaran agar peserta didik secara aktif mengembangkan potensi dirinya untuk memiliki kekuatan spiritual keagamaan, pengendalian diri, kepribadian, kecerdasan, akhlak mulia, serta keterampilan yang diperlukan dirinya, masyarakat, bangsa dan negara.

Seiring dengan perkembangan zaman, salah satu upaya yang telah dilakukan oleh pemerintah dalam perubahan pendidikan di Indonesia adalah melakukan perubahan kurikulum KTSP menjadi Kurikulum 2013.

Kurikulum 2013 merupakan penyempurnaan kurikulum sebelumnya yaitu KTSP tahun 2006 sebagai kurikulum operasional yang disusun dan dilaksanakan oleh masing-masing satuan pendidikan dengan memperhatikan dan berdasarkan kompetensi inti dan kompetensi dasar yang dikembangkan oleh Badan Standar Nasional Pendidikan (Suherman, 2014:71). Di tingkat sekolah dasar pada Kurikulum 2013, salah satu muatan pelajaran yang terdapat di dalamnya adalah muatan pelajaran IPS.

IPS merupakan bagian dari kurikulum yang membantu peserta didik dalam mengembangkan pengetahuan, keterampilan, sikap, nilai yang diperlukan untuk berpartisipasi dalam kehidupan masyarakat baik ditingkat lokal, nasional, maupun global (Maryani dan Syamsudin, 2009:5). Menurut Nursid (dalam Surahman dan Mukminan, 2017:3) bahwa Mata pelajaran IPS bertujuan mengembangkan potensi peserta didik agar peka terhadap masalah sosial yang terjadi dimasyarakat. Mata pelajaran IPS adalah salah satu mata pelajaran yang penting untuk diberikan kepada siswa di SD. Menurut Susanto (2014:7) "pelajaran IPS di SD mengajarkan konsep-konsep esensi ilmu sosial untuk membentuk subjek didik menjadi warga negara yang baik. Seorang guru tidak hanya dituntut untuk mampu menanamkan aspek pengetahuan saja dalam proses pembelajaran, akan tetapi juga menanamkan sikap sosial".

Sikap sosial sangat dibutuhkan untuk menjalin hubungan dengan orang lain dalam kehidupan sehari-hari. Menurut Rufaida (2014:4) "sikap sosial merupakan suatu tindakan seseorang untuk hidup dalam masyarakatnya seperti saling membantu, saling menghormati, saling berinteraksi, dan sebagainya". Selain itu dapat diartikan sebagai satu sikap yang terarah kepada tujuan-tujuan sosial, sebagai lawan dari sikap yang terarah kepada tujuan-tujuan pribadi Chaplin (dalam Lestari, 2015:23). Menurut Djaali (dalam Anisabellah 2017:16) sikap sosial meliputi sikap bertanggung jawab, peduli, jujur, percaya diri, bekerja dalam kelompok, dan santun.

Berdasarkan dari hasil pengamatan di lapangan sikap sosial siswa terlihat masih rendah. Hal tersebut terlihat dari adanya siswa yang memiliki kebiasaan berangkat tanpa meminta izin kepada guru di kelas, konsentrasi siswa saat pembelajaran di kelas masih kurang, siswa sering tidak selesai mengerjakan tugas dalam waktu yang telah ditentukan, bercanda dengan teman selama mengerjakan tugas, dan masih sering saling menggangu temannya. Sikap sosial yang buruk 
tersebut berpengaruh terhadap hasil belajar IPS siswa dan terdapat beberapa kendala dalam kegiatan pembelajaran di kelas.

Dari hasil observasi dan wawancara yang telah dilaksanakan di lapangan, terdapat beberapa kendala dalam kegiatan pembelajaran IPS di kelas. Selain sikap sosial siswa yang kurang baik, model pembelajaran yang diterapkan pada kegiatan pembelajaran kurang efektif. Guru mengunakan metode ceramah, penugasan dan tanya jawab dalam pembelajaran, kurang bervariasinya model dan media pembelajaran yang digunakan dalam proses pembelajaran, masih banyak siswa yang mengalami kesulitan dalam pembelajaran IPS. Dengan demikian, hasil belajar siswa menjadi kurang maksimal. Hal ini berdampak pada hasil UTS siswa yang belum memenuhi Kriteria Ketuntasan Minimum (KKM). Nilai UTS IPS Kelas IV SD Gugus IV Kecamatan Susut pada Tabel 01.

Tabel 01

Nilai UTS IPS Kelas IV SD Gugus IV Kecamatan Susut

\begin{tabular}{llcccc}
\hline N & Nama Selolah & KKM & $\begin{array}{c}\text { Presentase } \\
\text { Siswa di } \\
\text { Bawah KKM }\end{array}$ & $\begin{array}{c}\text { Rata-rata } \\
\text { Nilai }\end{array}$ & Jumlah Siswa \\
\hline 1 & SD N 1 Demulih & 65 & $70 \%$ & 53,03 & 40 \\
\hline 2 & SD N 2 Demulih & 60 & $60 \%$ & 58,08 & 5 \\
\hline 3 & SD N 3 Demulih & 65 & $69 \%$ & 50,38 & 13 \\
\hline 4 & SD N 3 Abuan & 65 & $84 \%$ & 49,96 & 26 \\
\hline 5 & SD N 2 Susut & 65 & $78 \%$ & 51,57 & 19 \\
\hline 6 & SD N 3 Susut & 60 & $66 \%$ & 52,05 & 12 \\
\hline
\end{tabular}

Tabel 0.1, menunjukkan nilai UTS IPS di kelas IV SD Gugus IV Kecamatan Susut masih tergolong rendah. Hal ini terbukti masih banyak siswa yang belum mencapai KKM. Dalam pembelajaran, guru cenderung menggunakan model pembelajaran konvensional yang didominasi oleh metode ceramah. Menurut Sanjaya (dalam Ibrahim, 2017:202) menyatakan bahwa pada pembelajaran konvensional siswa ditempatkan sebagai obyek belajar yang berperan sebagai penerima informasi secara pasif. Menurut Santyasa (2005:37) "pembelajaran konvensional bersifat teacher directed." Berdasarkan pendapat tersebut dapat diketahui pembelajaran konvensional adalah rangkaian kegiatan pembelajaran yang didominasi oleh guru, sedangkan siswa hanya mengandalkan guru sebagai sumber informasi. Didominasinya pembelajaran dengan metode ceramah menyebabkan pembelajaran menjadi pasif dan membuat siswa menjadi bosan dalam mengikuti pembelajaran. Peristiwa ini menyebabkan sikap sosial dan hasil belajar IPS siswa menjadi kurang optimal. Ruhimat, dkk., (2016) menyatakan hasil belajar siswa dipengaruhi oleh faktor internal dan faktor eksternal. Faktor internal, yaitu faktor-faktor yang ada dalam diri siswa meliputi faktor fisiologis dan faktor psikologis. Faktor eksternal, yaitu faktor-faktor yang berada di luar diri siswa meliputi faktor sosial, fartor budaya, faktor lingkungan fisik dan faktor spiritual. Salah satu upaya yang dapat dilakukan untuk mengatasi permasalahan di atas adalah dengan menerapkan model pembelajaran Trikaya Parisudha. Model pembelajara Trikaya Parisudha (MPTP) adalah salah satu model pembelajaran yang menekankan pada sikap dan memberikan kesempatan pada siswa untuk lebih aktif saat proses pembelajaran berlangsung.

Astawan, dkk. (2018) Dalam model pembelajaran Trikaya Parisudha siswa diharapkan mampu mencerminkan sikap sosial. Sikap sosial sangat berkaitan dengan model Trikaya Parisudha, karena setiap sintaks dari model Trikaya Parisudha lebih menekankan pada sikap. Guru dan siswa bersama-sama mengupayakan untuk selalu berpikir yang baik dan benar (manacika) selama pembelajaran, guru dan siswa selalu berbicara yang baik dan benar (wacika) selama pembelajaran, dan guru dan siswa selalu berbuat yang baik dan benar (kayika) selama pembelajaran.

Model pembelajaran Trikaya Parisudha dalam pembelajaran IPS di SD, dikaitkan dengan masalah-masalah atau kejadian yang terjadi di lingkungan sekitar menjadi bahan materi pelajaran. 
Setyosari (dalam Fathurrohman 2006:4) pembelajaran berbasis masalah adalah suatu metode atau cara pembelajaran yang ditandai oleh adanya masalah nyata, a real-world problems sebagai konteks bagi mahasiswa untuk belajar kritis dan ketrampilan memecahkan masalah dan memperoleh pengetahuan. Materi IPS yang dipelajari di SD merupakan berbagai peristiwa kehidupan yang dapat muncul dan ditemui peserta didik sehari-hari. Tugas seorang guru adalah menghubungkan pengalaman di sekitar peserta didik. Artinya guru bertugas menjembatani penalaran peserta didik dengan kejadian di lingkungan sekitar, agar pemahaman konsep IPS yang dipelajari dapat diterapkan peserta didik dalam kehidupan sehari-hari.

Berdasarkan hal tersebut, maka dalam penelitian ini akan dilakukan penelitian dengan menggunakan model pembelajaran Trikaya Parisudha berbasis masalah dalam mata pelajaran IPS. Dengan adanya model pembelajaran Trikaya Parisudha berbasis masalah ini diharapkan mampu mempengaruhi siswa dalam proses pembelajaran, serta diharapkan sikap sosial dan hasil belajar siswa dalam mata pelajaran IPS dapat tercapai. Untuk itu penelitian ini berjudul "Pengaruh Model Pembelajaran Trikaya Parisudha Berbasis Masalah Terhadap Sikap Sosial dan Hasil Belajar IPS Siswa Kelas IV SD Di Gugus IV Kecamatan Susut Tahun Pelajaran 2018/2019".

\section{METODE PENELITIAN}

Penelitian dengan metode eksperimental adalah bertujuan untuk meneliti hubungan sebab akibat dengan memanipulasikan satu atau lebih variabel pada satu atau lebih kelompok eksperimen dan membandingkan hasilnya dengan kelompok kontrol yang tidak mengalami manipulasi, Rakhmat (dalam Styanto, 2006:39). Rancangan penelitian yang digunakan adalah non equivalent post-test only control group design. Populasi dalam penelitian ini adalah semua siswa kelas V SD di Gugus IV Kecamatan Susut sebanyak 115 orang. Sebaran populasi dapat dilihat pada Tabel 02.

Tabel 02

Distribusi Sumber Populasi

\begin{tabular}{llc}
\hline No & \multicolumn{1}{c}{ Nama Sekolah } & Jumlah Siswa \\
\hline 1 & SD N 1 Demulih & 40 \\
\hline 2 & SD N 2 Demulih & 5 \\
\hline 3 & SD N 3 Demulih & 13 \\
\hline 4 & SD N 3 Abuan & 26 \\
\hline 5 & SD N 2 Susut & 19 \\
\hline 6 & SD N 3 Susut & 12 \\
\hline & & Total \\
\hline
\end{tabular}

Dalam penelitian ini, sampel ditentukan dengan menggunakan group random sampling (Agung, 2017). Sebelum menetapkan sampel penelitian terlebih dahulu dilakuan uji kesetaraan pada masing-masing kelas. Hasil uji kesetaraan diperoleh hasil bahwa seluruh kelas kelas IV SD Gugus IV Kecamatan Susut memiliki kemampuan yang setara. Untuk menentukan kelas eksperimen dan kontrol, peneliti melakukan sistem undian. Hasil undian tersebut IV SD N 3 Abuan dipilih sebagai kelas eksperimen dan IV SD N 2 Susut sebagai kelas kontrol.

Data pada penelitian ini dikumpulkan dengan beberapa metode pengumpulan data yang disesuaikan dengan permasalahan yang dikaji pada penelitian ini. Sesuai dengan permasalahannya maka data yang diperlukan, yaitu sikap sosial dan hasil belajar IPS. penelitian ini data hasil belajar IPS diperoleh melalui tes objektif dan sikap sosial melalui pemberian kuisioner.

Hasil penelitian ini dianalisis bertahap yaitu: analisis deskriptif dan inferensial. Uji prasyarat yang dilakukan adalah uji normalitas sebaran data, uji homogenitas varians, dan uji korelasi antar variable terikat. Uji normalitas dilakukan untuk meyakinkan bahwa sampel berasar dari populasi yang berdistribusi normal, sehingga uji hipotesis dapat dilakukan. Uji normalitas data dilakukan 
pada empat kelompok data yaitu: 1) data sikap sosial kelompok eksperimen, 2) data sikap sosial kelompok kontrol, 3) hasil belajar IPS eksperimen dan 4) hasil Belajar IPS kelompok kontrol.

Uji homogenitas dimaksud untuk memperlihatkan bahwa dua atau lebih kelompok data sampel berasal dari populasi yang memiliki varian yang sama, sedangkan uji kolerasi antara variabel terikat diakukan untuk mengetahui apakah apakah kolerasi antar variabel terikat tersebut tinggi atau rendah. Karena, jika antar variable terikat tinggi maka variable terikat tidak dapat dipisahkan, sedangkan jika kolerasi antar variable terikat rendah atau tidak ada kolerasi variabel terikat dalam penelitian ini dapat dipisahkan. Data dianalisis menggunakan uji dengan bantuan SPSS 17.00 for windows pada taraf signifikasi $5 \%$.

\section{HASIL PENELITIAN DAN PEMBAHASAN}

\section{HASIL PENELITIAN}

Hasil penelitian secara deskriptif memaparkan tentang hasil perhitungan mean, standar deviasi, range, skor/nilai maksimum, skor/nilai, minimum. Berdasarkan analisis deskriptif yang dilakukan terdapat empat skor/nilai menunjukan bahwa secara deskriptif kelompok siswa yang dibelajarkan menggunakan model pembelajaran Trikaya Parisudha berbasis masalah tinggi dibandingkan kelompok siswa yang dibelajarakan dengan model pembelajaran konvensional.

Berdasarkan analisis data deskriptif, tampak bahwa sikap sosial dan hasil belajar IPS siswa yang menggunakan model pembelajaran Trikaya Parisudha berbasis masalah lebih baik daripada model pembelajaran konvensional. Hal ini ditunjukan oleh rata-rata nilai sikap sosial siswa yang belajar menggunakan model pembelajaran Trikaya Parisudha berbasis masalah adalah 111,69, sedangkan rata-rata nilai sikap sosial siswa yang menggunakan model pembelajaran konvensional adalah 88,79. Nilai rata-rata hasil belajar IPS siswa yang belajar menggunakan model pembelajaran Trikaya Parisudha berbasis masalah adalah 18,60, sedangkan rata-rata siswa yang menggunakan model pembelajaran konvesional 13,53. Dapat disimpulkan bahwa sikap sosial dan hasil belajar IPS siswa yang menggunakan model pembelajaran Trikaya Parisudha berbasis masalah lebih baik daripada siswa yang menggunakan model pembelajaran konvensional.

Hasil uji hipotesis dalam penelitian ini membuktikan bahwa: pertama, secara simultan, terdapat perbedaan perbedaan sikap sosial dan hasil belajar IPS antara siswa yang mengikuti model pembelajaran Trikaya Parisudha berbasis masalah dan siswa yang mengikuti model pembelajaran konvensional. Hasil analisis disajikan pada Tabel 03.

Tabel 03

Uji Multivariate Tests

\begin{tabular}{llrrrrr}
\hline & Effect & Value & F & $\begin{array}{r}\text { Hypothesis } \\
\text { df }\end{array}$ & Error df & Sig. \\
\hline \multirow{2}{*}{ Intercept } & Pillai's Trace & .997 & $6013.355^{\mathrm{a}}$ & 2.000 & 42.000 & .000 \\
\cline { 2 - 7 } & Wilks' Lambda & .003 & $6013.355^{\mathrm{a}}$ & 2.000 & 42.000 & .000 \\
\cline { 2 - 7 } & Hotelling's Trace & 286.350 & $6013.355^{\mathrm{a}}$ & 2.000 & 42.000 & .000 \\
\cline { 2 - 7 } & $\begin{array}{l}\text { Roy's Largest } \\
\text { Root }\end{array}$ & 286.350 & $6013.355^{\mathrm{a}}$ & 2.000 & 42.000 & .000 \\
\hline \multirow{5}{*}{ Kelas } & Pillai's Trace & .801 & $84.558^{\mathrm{a}}$ & 2.000 & 42.000 & .000 \\
\cline { 2 - 7 } & Wilks' Lambda & .199 & $84.558^{\mathrm{a}}$ & 2.000 & 42.000 & .000 \\
\cline { 2 - 6 } & Hotelling's Trace & 4.027 & $84.558^{\mathrm{a}}$ & 2.000 & 42.000 & .000 \\
\cline { 2 - 6 } & Roy's Largest & 4.027 & $84.558^{\mathrm{a}}$ & 2.000 & 42.000 & .000 \\
& Root & & & & \\
\hline
\end{tabular}


Tabel 04

Between-Subjects Effects

\begin{tabular}{|c|c|c|c|c|c|c|}
\hline & $\begin{array}{l}\text { Dependent } \\
\text { Variable }\end{array}$ & $\begin{array}{l}\text { Type III } \\
\text { Sum of } \\
\text { Squares }\end{array}$ & df & $\begin{array}{l}\text { Mean } \\
\text { Square }\end{array}$ & $F$ & Sig. \\
\hline \multirow{2}{*}{$\begin{array}{l}\text { Corrected } \\
\text { Model }\end{array}$} & Sikap Sosial & $5758.281^{a}$ & 1 & 5758.281 & 152.401 & .000 \\
\hline & $\begin{array}{l}\text { Hasil } \\
\text { Belajar IPS }\end{array}$ & $301.759^{b}$ & 1 & 301.759 & 31.698 & .000 \\
\hline \multirow[t]{2}{*}{ Intercept } & Sikap Sosial & 441229.215 & 1 & $\begin{array}{r}441229.21 \\
5 \\
\end{array}$ & $\begin{array}{r}11677.78 \\
6 \\
\end{array}$ & .000 \\
\hline & $\begin{array}{l}\text { Hasil } \\
\text { Belajar IPS }\end{array}$ & 11449.848 & 1 & 11449.848 & 1202.738 & .000 \\
\hline \multirow{2}{*}{ Model } & Sikap Sosial & 5758.281 & 1 & 5758.281 & 152.401 & .000 \\
\hline & $\begin{array}{l}\text { Hasil } \\
\text { Belajar IPS }\end{array}$ & 301.759 & 1 & 301.759 & 31.698 & .000 \\
\hline
\end{tabular}

Pada Tabel 03 Didapatkan nilai signifikan Pillai's Treace, Wilks'Lambda, Hotelling's Trice, dan Roy's Larget Root sebesar 0.000 dan lebih kecil dari 0,05. Sehingga dapat disimpulkan bahwa hipotesis nol $\left(\mathrm{H}_{0}\right)$ ditolak dan hipotesis alternatif $\left(\mathrm{H}_{1}\right)$ diterima. Jadi terdapat perbedaan secara simultan sikap sosial dan hasil belajar IPS antara siswa yang mengikuti model pembelajaran Trikaya Parisudha berbasis masalah dan siswa yang mengikuti pembelajaran konvensional pada siswa kelas IV di SD Gugus IV Kecamatan Susut tahun pelajaran 2018/2019.

Kedua, hasil analisis menunjukkan terdapat perbedaan sikap sosial antara siswa yang mengikuti model pembelajaran Trikaya Parisudha berbasis masalah dan siswa yang mengikuti pembelajaran konvensional. Adapun ringkasan analisis data hipotesis 2 dapat dilihat pada Tabel 04 dan Tabel 05.

Tabel 05

Pairwise Comparisons

\begin{tabular}{|c|c|c|c|c|c|c|c|}
\hline \multirow{2}{*}{$\begin{array}{l}\text { Dependent } \\
\text { Variable }\end{array}$} & \multirow{2}{*}{$\begin{array}{c}(\mathrm{I}) \\
\text { Kelompo } \\
\mathrm{k}\end{array}$} & \multirow{2}{*}{$\begin{array}{c}(\mathrm{J}) \\
\text { Kelompo } \\
\mathrm{k}\end{array}$} & \multirow{2}{*}{$\begin{array}{c}\text { Mean } \\
\text { Difference } \\
(I-J)\end{array}$} & \multirow{2}{*}{$\begin{array}{l}\text { Std. } \\
\text { Error }\end{array}$} & \multirow{2}{*}{ Sig. $^{a}$} & \multicolumn{2}{|c|}{$\begin{array}{l}\text { 95\% Confidence Interval for } \\
\text { Difference }^{a}\end{array}$} \\
\hline & & & & & & $\begin{array}{l}\text { Lower } \\
\text { Bound }\end{array}$ & Upper Bound \\
\hline \multirow[t]{2}{*}{$\begin{array}{l}\text { Sikap } \\
\text { Sosial }\end{array}$} & $\begin{array}{l}\text { Eksperim } \\
\text { en }\end{array}$ & Kontrol & $22.903^{\prime}$ & 1.855 & .000 & 19.161 & 26.644 \\
\hline & Kontrol & $\begin{array}{l}\text { Eksperim } \\
\text { en }\end{array}$ & $-22.903^{\circ}$ & 1.855 & .000 & $26.644^{-}$ & -19.161 \\
\hline \multirow{2}{*}{$\begin{array}{l}\text { Hasil } \\
\text { Belajar } \\
\text { IPS }\end{array}$} & $\begin{array}{l}\text { Eksperim } \\
\text { en }\end{array}$ & Kontrol & $5.243^{\circ}$ & .931 & .000 & 3.365 & 7.121 \\
\hline & Kontrol & $\begin{array}{l}\text { Eksperim } \\
\text { en }\end{array}$ & $-5.243^{n}$ & .931 & .000 & -7.121 & -3.365 \\
\hline
\end{tabular}

Berdasarkan Tabel 04, nilai signifikansi menunjukan bahwa nilai signifikan sikap sosial pada kolom model sebesar 0.000 dan lebih kecil dari 0.05 . sehingga dapat disimpulkan bahwa hipotesis nol $\left(\mathrm{H}_{0}\right)$ ditolak dan hipotesis alternatif $\left(\mathrm{H}_{1}\right)$ diterima. Hal ini berarti bahwa terdapat perbedaan yang signifikan sikap sosial antara kelompok siswa yang dibelajarkan dengan model pembelajaran Trikaya Parisudha berbasis masalah dan kelompok siswa yang dibelajarkan dengan pembelajaran konvensional pada siswa kelas IV di SD Gugus IV Kecamatan Susut Tahun Pelajaran 2018/2019. Kemudian ditindaklanjuti pada Tabel 05, pada kolom sikap sosial, nilai Mean Difference (I-J) sebesar 22.903 (bernilai positif) dengan signifikansi sebesar $0.000<0,05$ yang artinya kelompok eksperimen lebih baik dari kelompok kontrol. Dengan kata lain, siswa yang dibelajarkan dengan 
model pembelajaran Trikaya Parisudha berbasis masalah lebih unggul daripada siswa yang dibelajarkan dengan model pembelaaran konvensional pada penilaian sikap sosial.

Ketiga, hasil analisis menunjukan bahwa nilai signifikan hasil belajar IPS pada kolom Corrected Model sebesar 0.000 dan lebih kecil dari 0.05. sehingga dapat disimpulkan bahwa hipotesis nol $\left(\mathrm{H}_{0}\right)$ ditolak dan hipotesis alternatif $\left(\mathrm{H}_{1}\right)$ diterima. Hal ini berarti bahwa terdapat perbedaan hasil belajar IPS antara kelompok siswa yang dibelajarkan dengan model pembelajaran Trikaya Parisudha berbasis masalah dan kelompok siswa yang dibelajarkan dengan pembelajaran konvensional pada siswa kelas IV di SD Gugus IV Kecamatan Susut Tahun Pelajaran 2018/2019. Kemudian ditindaklanjuti Tabel 05 pada kolom hasil belajar IPS, nilai Mean Difference (I-J) sebesar 5.243 (bernilai positif) dengan signifikansi sebesar $0.000<0,05$ yang artinya kelompok eksperimen lebih baik dari kelompok kontrol. Dengan kata lain, siswa yang dibelajarkan dengan model pembelajaran Trikaya Parisudha berbasis masalah lebih unggul daripada siswa yang dibelajarkan dengan model pembelaaran konvensional pada penilaian hail belajar IPS.

\section{PEMBAHASAN}

Temuan pertama, temuan analisis data tentang sikap sosial dan hasil belajar IPS menunjukkan bahwa terdapat perbedaan yang simultan antara siswa yang mengikuti model pembelajaran Trikaya Parisudha berbasis masalah dengan siswa yang mengikuti pembelajaran konvensional pada siswa kelas IV SD di Gugus IV Kecamatan Susut. Sikap sosial pada kelas eksperimen sangat berkembang dengan pembelajaran Trikaya Parisudha berbasis masalah. Perkembangan sikap sosial juga secara tidak langsung mendorong peningkatan hasil belajar IPS siswa. Salah satu indikator dari sikap sosial yaitu sikap percaya diri, sikap percaya diri siswa terlihat jelas pada fase wacika hal tersebut terlihat dari siswa yang berani mengemukakan pendapatnya kepada tamannya saat berdiskusi. Selain percaya diri sikap disiplin juga terlihat pada fase kayika, kedisiplinan siswa menetukan hasil belajar siswa, semakin disiplin siswa maka hasil belajar siswa semakin meningkat. Sikap percaya diri dan sikap disiplin tersebut membuat siswa menjadi lebih aktif di dalam proses pembelajaran dan tentunya akan berdampak pada hasil belajar IPS siswa.

Temuan kedua Temuan analisis data tentang sikap sosial menunjukkan bahwa terdapat perbedaan antara siswa yang mengikuti model pembelajaran Trikaya Parisudha berbasis masalah dengan siswa yang mengikuti pembelajaran konvensional pada siswa kelas IV SD di Gugus IV Kecamatan Susut. Meningkatnya sikap sosial siswa dalam pembelajaran disebabkan karena model pembelajaran Trikaya Parisudha berbasis masalah memberikan dampak terbentuknya karakter positif yang mencerminkan karakter Trikaya Parisudha. Karakter Trikaya Parisudha yang berkaitan dengan indikator sikap sosial yaitu karakter wacika, yang memberikan kesempatan bagi siswa untuk berani mengemukakan pendapat dengan pecaya diri dan karakter kayika, yang mengembangkan disiplin siswa dilihat dari proses pembelajaran yang antusias namun tetap terkendali. Dengan ditanamkan karakter Trikaya Parisudha tersebut maka sikap sosial siswa menjadi lebih baik.

Temuan ketiga Temuan analisis data tentang hasil belaar IPS menunjukkan bahwa terdapat perbedaan antara siswa yang mengikuti model pembelajaran Trikaya Parisudha berbasis masalah dengan siswa yang mengikuti pembelajaran konvensional pada siswa kelas IV SD di Gugus IV Kecamatan Susut. Hasil belajar IPS kelompok eksperimen yang meningkat setelah mengikuti model pembelajaran Trikaya Parisudha berbasis masalah yang diebabkan adanya perbedaan perlakuan aktivitas belajar. Model pembelajaran Trikaya Parisudha berbasis masalah memberikan kesempatan kepada siswa untuk melakukan kegiatan-kegiatan belajar secara aktif. Fase kayika peran siswa lebih dominan dibandingkan guru, siswa lebih aktif melakukan pengamatan secara berkolaborasi, sementara guru mendampingi kelompok yang mengalami kendala. Fase wacika, peran siswa juga lebih dominan dibandingkan guru, siswa aktif mempreentasikan hail pengamatan, menanggapi, dan mendiskusika satu sama lain. Sementara guru menadi moderator untuk memfasilitasi jalannya diskusi. Fase manacika, peran siswa tetap lebih dominan dibandingkan guru, siswa melakukan refleksi terhadap hasil pengamatan dan hasil diskusi melalui 
menyelesaikan permasalahan yang diberikan. Memberikan siswa lebih aktif dalam proses pembelajaran dapat meningkatkan hasil belajar IPS siswa.

\section{SIMPULAN}

Berdasarkan hasil pengujian hipotesis dan pembahasan, maka simpulan penelitian ini adalah sebagai berikut. 1) Terdapat perbedaan secara simultan sikap sosial dan hasil belajar IPS antara siswa yang mengikuti model pembelajaran Trikaya Parisudha berbasis masalah dan siswa yang mengikuti pembelajaran konvensional pada siswa kelas IV di SD gugus IV Kecamatan Susut tahun pelajaran 2018/2019. Sikap sosial dan hasil belajar IPS pada siswa yang mengikuti model pembelajaran Trikaya Parisudha berbasis masalah lebih tinggi dibandingkan siswa yang mengikuti model pembelajaran konvensional. Hal ini dibuktikan dari analisis Pillai's Treace, Wilks'Lambda, Hotelling's Trice, dan Roy's Larget Root sebesar $0.000<0,05$. Hal ini berarti, terdapat pengaruh yang signifikan model pembelajaran Trikaya Parisudha berbasis masalah terhadap sikap sosial dan hasil belajar IPS siswa kelas IV SD di gugus IV Kecamatan Susut tahun pelajaran 2018/2019. 2) Terdapat perbedaan sikap sosial antara kelompok siswa yang dibelajarkan dengan model pembelajaran Trikaya Parisudha berbasis masalah dan kelompok siswa yang dibelajarkan dengan pembelajaran konvensional pada siswa kelas IV di SD Gugus IV Kecamatan Susut tahun pelajaran 2018/2019. Sikap sosial pada siswa yang mengikuti model pembelajaran Trikaya Parisudha berbasis masalah lebih tinggi dibandingkan siswa yang mengikuti model pembelajaran konvensional. Hal ini di buktikan dengan analisis Between-Subjects Effects menunjukkan nilai sig sebesar $0.000<0.05$. Di samping ini, analisis Pairwise Comparisons dengan nilai pada kolom sikap sosial, nilai Mean Difference (I-J) sebesar 22.903 (bernilai positif) dengan signifikansi sebesar $0.000<0,05$. Hal ini berarti, terdapat pengaruh yang signifikan model pembelajaran Trikaya Parisudha berbasis masalah terhadap sikap sosial pada siswa kelas IV di SD Gugus IV Kecamatan Susut tahun pelajaran 2018/2019. 3) Terdapat perbedaan hasil belajar IPS antara kelompok siswa yang dibelajarkan dengan model pembelajaran Trikaya Parisudha berbasis masalah dan kelompok siswa yang dibelajarkan dengan pembelajaran konvensional pada siswa kelas IV di SD Gugus IV Kecamatan Susut tahun pelajaran 2018/2019. Hasil belajar IPS pada siswa yang mengikuti model pembelajaran Trikaya Parisudha berbasis masalah lebih tinggi dibandingkan siswa yang mengikuti model pembelajaran konvensional. Hal ini di buktikan dengan analisis Between-Subjects Effects menunjukkan nilai sig sebesar $0.000<0.05$. Di samping ini, analisis Pairwise Comparisons dengan nilai pada kolomhasil belajar IPS, nilai Mean Difference (IJ) sebesar 5.243 (bernilai positif) dengan signifikansi sebesar $0.000<0,05$. Hal ini berarti, terdapat pengaruh yang signifikan model pembelajaran Trikaya Parisudha berbasis masalah terhadap hasil belaar IPS pada siswa kelas IV di SD Gugus IV Kecamatan Susut tahun pelajaran 2018/2019.

\section{SARAN}

Berdasarkan temuan-temuan dalam penelitian ini, dapat disampaikan saran-saran sebagai berikut: 1) Kepada Guru IPS SD agar lebih inovatif dalam memilih model pembelajaran dan media pembelajaran yang akan diterapkan pada proses pembelajaran. 2) Kepala Sekolah disarankan agar dapat menciptakan kondisi yang mampu mendorong para guru untuk mencoba menerapkan model pembelajaran Trikaya Parisudha berbasis masalah dalam pembelajaran IPS khususnya dan mata pelajaran lain pada umumnya dalam upaya meningkatkan sikap sosial dan hasil belajar siswa. 3) Peneliti yang berminat untuk mengadakan penelitian lebih lanjut tentang model pembelajaran Trikaya Parisudha berbasis masalah dalam bidang ilmu lainnya. Penelitian ini sebagai bahan pertimbangan untuk perbaikan dan penyempurnaan penelitian yang akan dilaksanakan.

\section{UCAPAN TERIMAKASIH}

Ucapan terimakasih penulis ucapkan kepada seluruh pihak yang telah membantu terselesaikannya penelitian ini. Terimakasih juga disampaikan kepada pimpinan redaksi Mimbar PGSD Undiksha atas kesediannya menerbitkan jurnal ini. 


\section{DAFTAR RUJUKAN}

Agung, A.A. G. 2017. Evaluasi Pendidikan. Edisi-4. Singaraja: Undiksha.

Anisabellah. 2017. "Pengaruh Sikap Sosial Terhadap Prestasi Belajar Mata Pelajaran IPS Siwa Kelas VIII Di MTs AL-Maarif 01 Singosari Malang". Tersedia pada http://etheses.uinmalang.ac.id/9239/1/13130118.pdf (diakses pada 20 Februari 2019).

Astawan, I G, I Gusti Putu Suryadarma, dan Sujarwo. 2018. Teori dan Aplikasi Model Pembelajaran Trikaya Parisudha di Sekolah Dasar. Singaraja: Undiksha Press.

Ibrahim. 2017. "Perpaduan Model Pembelajaran Aktif Konvensional (Ceramah) Dengan Cooperatif (Make - A Match) Untuk Meningkatkan Hasil Belajar Pendidikan Kewarganegaraan". Jurnal IImu Pendidikan Sosial, Sains, dan Humaniora, Volume 3, Nomor 2 (hlm. 199-211).

Fathurrohman. 2006. "Model-model Pembelajaran". Tersedia pada http://staffnew.uny.ac.id/upload/132313272/pengabdian/model-model-pembelajaran.pdf (diakses pada 20 Februari 2019) .

Lestari, Dwi. 2015. "Identifikasi Sikap Sosial Siswa Kelas V Sd". Tersedia pada http://journal.student.uny.ac.id/ojs/index.php/pgsd/article/view/517/483. (diakses pada 15 Januari 2018) .

Ruhimat, Ibrahim dkk 2016. Kurikulum dan Pembelajaran. Jakarta: Rajawali Pers.

Rufaida, D. 2013. "Pengembangan Sikap Sosial Siswa Menggunakan Pendekatan Pakem Pada Pembelajaran IPS Kelas Vb Sd Negeri Mangiran, Kecamatan Srandakan, Kabupaten Bantul". Tersedia pada https://eprints.uny. ac.id /15615/. (diakses tanggal 15 Januari 2019).

Santyasa, I W. 2005. Buku Ajar Belajar dan Pembelajaran. Singaraja: Undiksha Press.

Suherman. 2014. “Implementasi Kurikulum Baru Tahun 2013 Mata Pelajaran Pendidikan Jasmani”. Mimbar Sekolah Dasar. Volume 1. Nomor 1 (hlm 71-76)

Surahman, E. dan Mukminan 2017. "Peran Guru IPS Sebagai Pendidik Dan Pengajar Dalam Meningkatkan Sikap Sosial dan Tanggung Jawab Sosial Siswa SMP”. Jurnal Pendidikan IPS, Volume 4, Nomor 1 (hlm. 1-13).

Susanto, A. 2014. Pengembangan Pembelajaran IPS di Sekolah Dasar. Jakarta: Kencana Prenada Media Group.

Styanto, E. 2006. "Memperkenalkan Kembali Metode Eksperimen dalam Kajian”. Jurnal IImu Komunikasi. Volume 3. Nomor 1 (hlm 37-48)

Trianto. 2009. Mendesain Model Pembelajaran Inovatif-Progresif. Jakarta: Kencana Prenada Media Group.

Undang-Undang Republik Indonesia Nomor 20 Tahun 2003 Tentang Sistem Pendidikan Nasiona. Jakarta: Kementrian Pendidikan Nasional. 